\title{
Characteristics of the mechanically fastened joints of one-layer bitumen sheets
}

\author{
Tomáš Petř́iček ${ }^{1, *}$, Petr Kacálek ${ }^{1}$, and Tomáš Hlavačka ${ }^{1}$ \\ ${ }^{1}$ Brno University of Technology, Faculty of Civil Engineering, \\ Institute of Building Structures, Veveř́ 95, 60200 Brno, Czech Republic
}

\begin{abstract}
The system of mechanic fastening is one of the most frequently used variants of roof membrane stabilization against the impacts of wind sucking. With the growing number of applications of mechanically fastened roofs the number of defects is also growing. We particularly see them in the joints of waterproofing membranes. The contribution is thus dedicated to examination of mutual dependence between the type of the carrier and the strength characteristics of mechanically fastened joints of these sheets. Bitumen sheets with different types of carrier used for onelayer mechanically fastened waterproofing membranes of flat roofs were chosen as samples. The above mentioned dependence is frequently stated in the practice, but is not explicitly documented. The aim of the contribution is to confirm or refute a hypothesis that a relation between the bitumen sheet carrier type and the strength of their joints exists. The results were arranged on the base of statistic evaluation of data obtained by laboratory measurement.
\end{abstract}

\section{Introduction}

The application of the single-layer mechanically fastened bitumen sheet system is a quick and progressive one, which requires high technological discipline. High quality bitumen sheets of at least $0.5 \mathrm{~mm}$ thickness are required as standard for the application of singlelayer systems. The bitumen sheets also need to be of a sufficient quality that they are weldable and flexible over the long term. The sheets are mostly reinforced with a combination of PES fleece strengthened with glass fibres laid in one or both directions. Overlaps of at least $120 \mathrm{~mm}$ wide are recommended for the sheets.

Whole surface melting of the joint is essential to the waterproofing capabilities of the system as well as for the transfer of wind load forces. A critical point with regards to the wind load resistance of a joint is the presence of a fastening element.

\section{Fastening of bitumen sheet joints}

To ensure the joint is sealed correctly the surface area along the entire joint length of both sheets need to be heated to melting point. The fastening element is not placed in the centre

\footnotetext{
* Corresponding author: petricek.t@,fce.vutbr.cz
} 
of the joint but is located $10 \mathrm{~mm}$ (or $20 \mathrm{~mm}$ ) from the edge of the lower sheet, whereby the entire surface area of the joint is able to take the strain of the fastening element. The effects of linear shearing (tear) force and the tangential forces (peel resistance) are therefore applied in varying degrees to the overlap over the entire surface area of the joint.

According to ČSN EN 13707 [1] manufacturers of bitumen sheets are obliged to produce them with sufficient resistance against tangential forces (Determination of peel resistance in joints according to ČSN EN 12316-1 [2]) and linear shear resistance when joined together (Determination of shear resistance according to ČSN EN 12317-1 [3], [4]).

A mechanically fastened bitumen sheet joint faces a combination of both the above stresses. As angle $\beta$ grows (see Fig. 1), the level of peel stress grows, whereas where angle $\beta$ (Fig. 2) is minimized, the linear shear force (tear) grows. Within this context, the peel resistance test of a joint is of particular importance when evaluating the quality of the bitumen substance used [5].

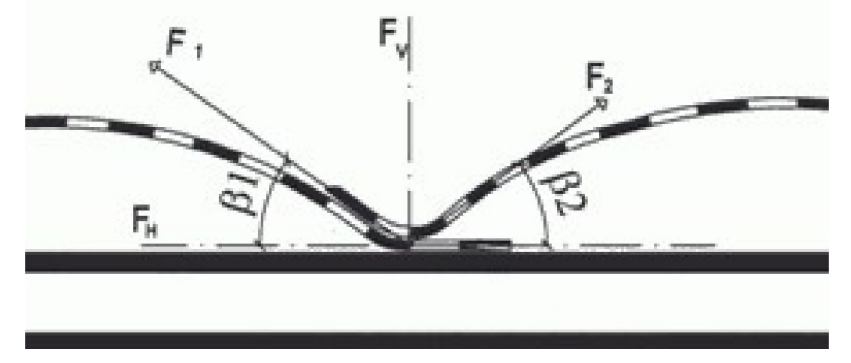

Fig. 1. Prevailing tangential (peel) force. Source: [6].

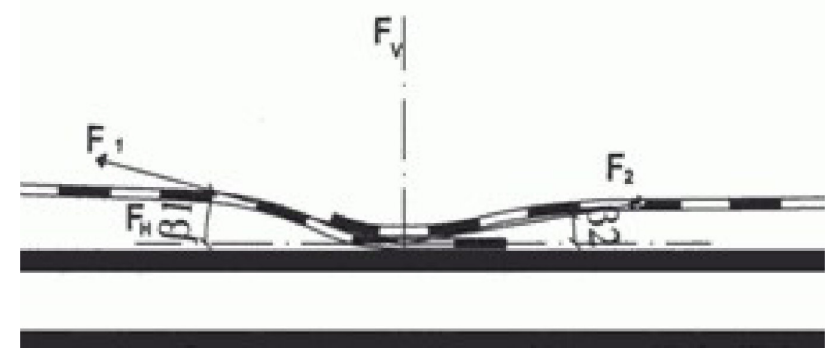

Fig. 2. Prevailing linear shear (tear) force. Source: [6].

The carrier in the bitumen sheet guarantees the strength properties, volume stability, it forms the base of the bitumen sheet during production and also traps and transfers tensile stresses and redistributes the stress caused by internal and external forces.

The resultant mechanical and strength characteristics of the carrier depend on the material base of the fibres, their mutual direction and on the proportion of the applied filler for their connection. Approximate comparison of the properties of carriers are shown in Table 1. 
Table 1. Approximate comparison of strength and ductility of the most often used carriers Source: [6].

\begin{tabular}{|c|c|c|c|c|c|}
\hline \multirow[b]{2}{*}{ Carrier type } & \multirow{2}{*}{$\begin{array}{c}\begin{array}{c}\text { Square } \\
\text { weight }\end{array} \\
\mathrm{g} / \mathrm{m}^{2}\end{array}$} & \multicolumn{2}{|c|}{ Strength } & \multicolumn{2}{|c|}{ Ductility } \\
\hline & & \begin{tabular}{|c|} 
longitudinal \\
direction \\
{$\left[\mathrm{kN} \cdot \mathrm{m} /{ }^{-1}\right]$}
\end{tabular} & $\begin{array}{c}\text { transversal } \\
\text { direction } \\
{\left[\mathrm{kN} \cdot \mathrm{m} /{ }^{-1}\right]}\end{array}$ & $\begin{array}{c}\text { longitudinal } \\
\text { direction } \\
{[\%]}\end{array}$ & $\begin{array}{c}\text { transversal } \\
\text { direction } \\
{[\%]}\end{array}$ \\
\hline Glass fleece (Vlis)* & $60-110$ & $\min .3 \cdot 6-8 \cdot 6$ & $\min .2 .6-4.8$ & $1.2-1.4$ & $1.2-1.4$ \\
\hline Glass woven fabric (rug)** & $152-200$ & $\min .18-21$ & $\min .20-24$ & $2-3$ & $2-3$ \\
\hline PES fleece*** & $120-250$ & $8.6-19$ & $4.6-14$ & $20-35$ & $23-37$ \\
\hline Combined**** & $160-180$ & $\min .9 .6-13.3$ & $\min .6 .8-8.1$ & $\min .23$ & $\min .25$ \\
\hline
\end{tabular}

Tests describing tensile properties provide comparison of the influence of the carrier on the overall strength parameters of a bitumen sheet: the highest tensile strength and ductility specified in the longitudinal and transversal direction. The graph in Fig. 3 shows comparison of mechanical properties of carriers and bitumen sheets with the respective carriers.

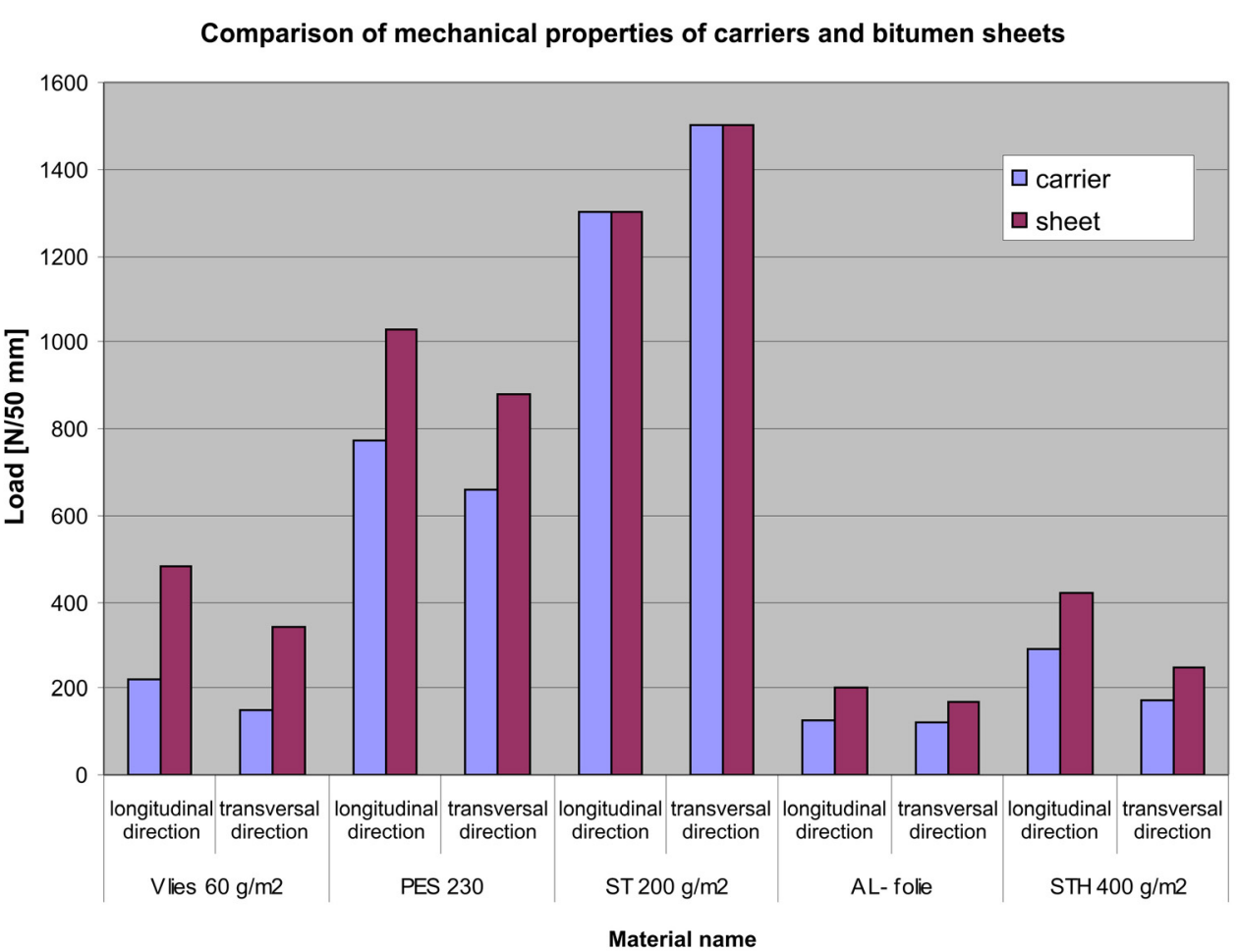

Fig. 3. Comparison of mechanical properties of carriers and bitumen sheets with respective carriers at the temperature of $+20^{\circ} \mathrm{C}$ Source: [6]. 


\section{Experimental measurement}

A pressure chamber was used in which the composition of a roof membrane from a real joint segment of mechanically fastened waterproofing could be subjected to defined stresses. This wind load test is defined in the Approval Guideline for systems of mechanically fastened waterproofing membranes ETAG 006 [7].

For the experimental measurements tests were carried out on a standard tensile testing machine. The specimens were roof membrane segments, not just the waterproofing membrane. Two metal fastening strips in the arms of the upper grip of the machine held the waterproofing membrane in place. These arms transferred the force of the applied stress to test material. A pad, to which the waterproofing membrane was fastened by thermal insulation, was clamped into the lower grip. As the lower grip of the tensile testing machine receded it caused stress on the joint and subsequently its rupture.

The test specimens were prepared according to composition variant S1 i.e. analogically for a roof without thermal insulation with the waterproofing membrane mechanically fastened to OSB board of $22 \mathrm{~mm}$ thickness. The fastening element to the hard base was a screw with a metal oval washer. The edge of the pressure washer of the fastening element was located $10 \mathrm{~mm}$ from the edge of the lower bitumen sheet. The use of the oval pressure washer was intentional because it provides better pressure on the lower sheet due to its larger surface area. As a result, the rupture of the test specimens was dependent on the parameters of the bitumen sheet rather than on the failure of the fastening element.

Three bitumen sheet variants were chosen as the waterproofing membranes:

1. Test specimen B - SBS modified bitumen sheet $5.2 \mathrm{~mm}$ thick, carrier: PES $180 \mathrm{~g} / \mathrm{m}^{2}$ reinforced longitudinally with glass fibres, flexibility at low temperatures: $-25^{\circ} \mathrm{C}$, joint length $100 \mathrm{~mm}$

2. Test specimen $\mathbf{E}$ - SBS modified bitumen sheet $5.2 \mathrm{~mm}$ thick, carrier: PES $230 \mathrm{~g} / \mathrm{m}^{2}$, unreinforced, flexibility at low temperatures: $-25^{\circ} \mathrm{C}$, joint length $100 \mathrm{~mm}$

3. Test specimen F - SBS modified bitumen sheet $5.2 \mathrm{~mm}$ thick, carrier: PES $180 \mathrm{~g} / \mathrm{m}^{2}$, reinforced on both sides with glass fibres, flexibility at low temperatures: $-25{ }^{\circ} \mathrm{C}$, joint length $100 \mathrm{~mm}$

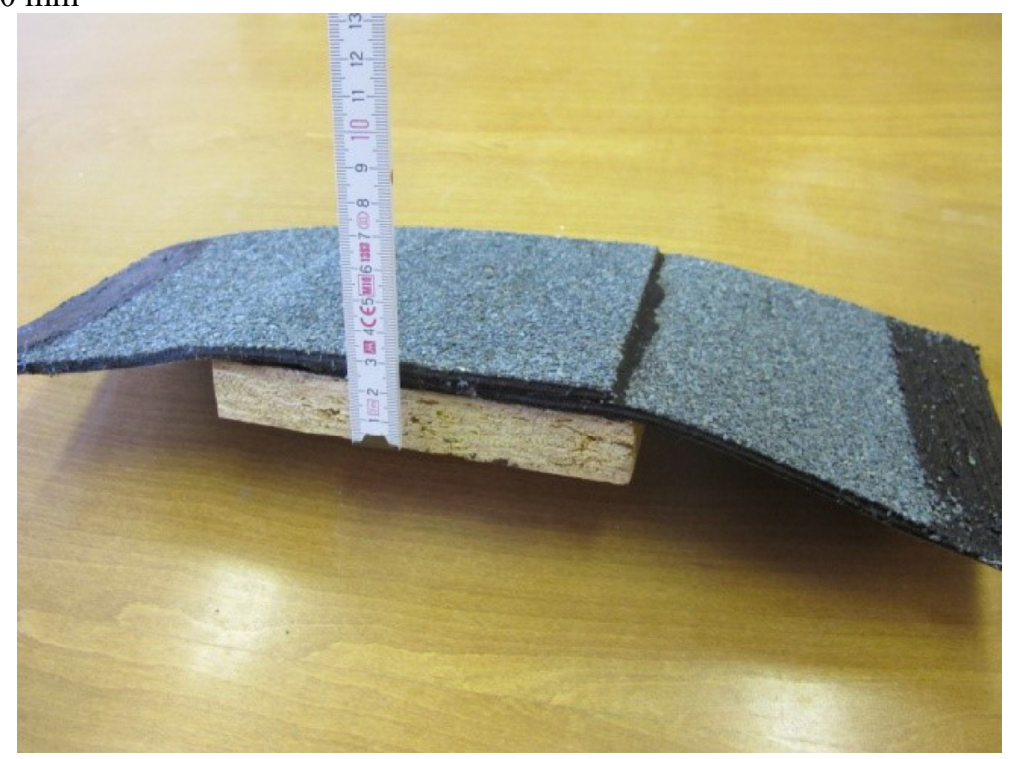

Fig. 4. Test specimen - composition variant S1. Source: [8]. 


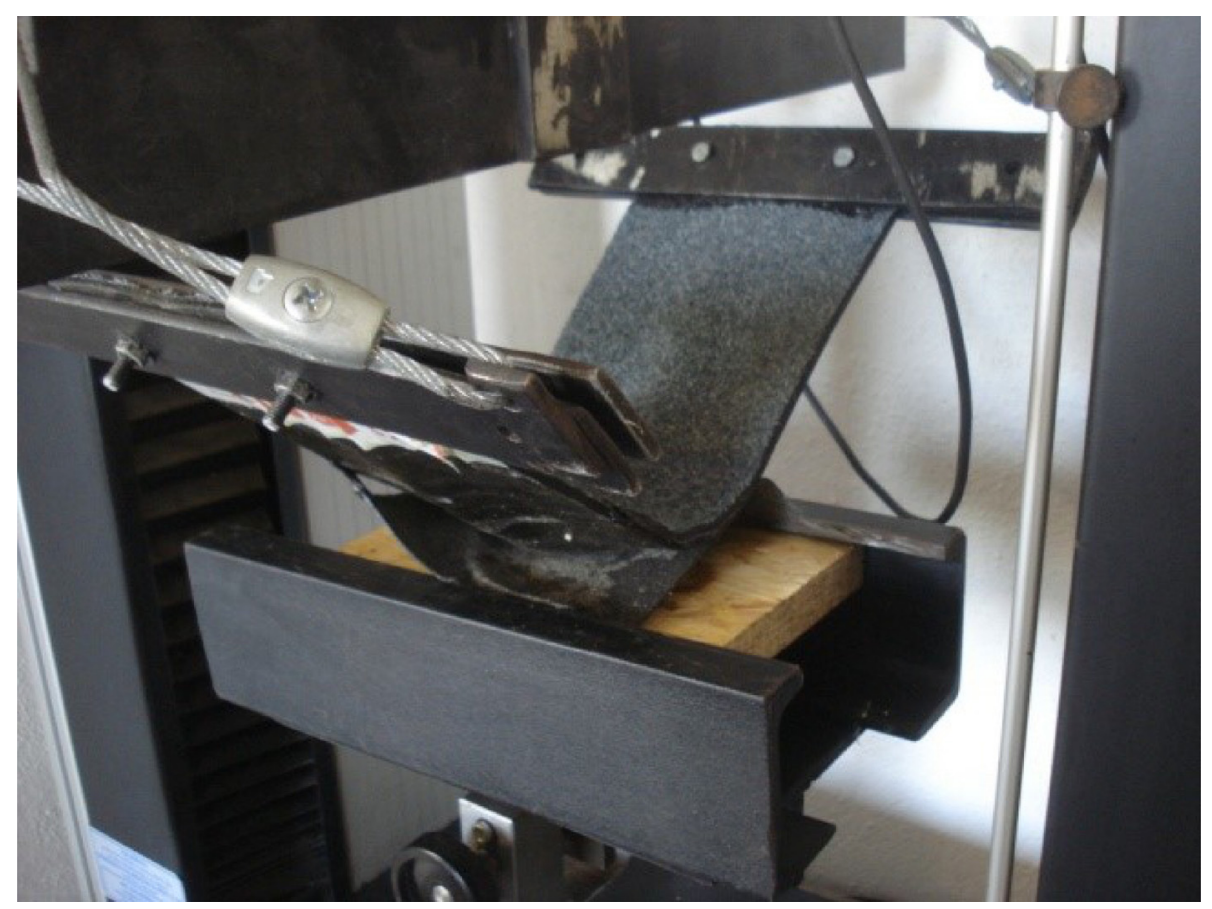

Fig. 5. Test specimen in the tensile testing machine during testing. Source: [8].

\section{Evaluation}

Approximately 10 specimens were used for each test sample. The final force is in the form $\bar{x} \pm \bar{\vartheta}(\bar{x})$, where $\bar{x}$ is the arithmetic average and $\bar{\vartheta}(\bar{x})$ is the probable measurement error. The latter was determined on the basis of the error theory for the deviations of the arithmetic average using the formula:

$$
\bar{\vartheta}(\bar{x})=\frac{2}{3} \sqrt{\frac{1}{n(n-1)} \sum_{i=1}^{n}\left(x_{i}-\bar{x}\right)^{2}} .
$$

\section{Results of the experimental measurement and discussion}

In the specimens with lower square weight ( $\mathrm{B}$ and $\mathrm{F}$ ) unsealing of the joint occurred and the test ended in tearing of the carrier on the base of the fastening element and in separation of the waterproofing layer from the base (Fig. 6). The strength of specimen E exceeded the range of the testing machine (max. tensile $2,000 \mathrm{~N}$ ), the coherence of the specimen $\mathrm{E}$ was so high that no unsealing of the joint occurred in some of the samples (Fig. 7).

We can assume on the base of the results of the experimental measurement that the strength of a mechanically fastened joint grows with the square weight of the PES rug used in the bitumen sheet carrier. Specimen E (unreinforced PES rug, $230 \mathrm{~g} / \mathrm{m}^{2}$ ) achieved the highest strength values, the results of specimen B (PES rug longitudinally reinforced with glass fibre, $180 \mathrm{~g} / \mathrm{m}^{2}$ ) were by approximately $13 \%$ lower. Specimen F (PES rugs reinforced with glass fibre on both sides $180 \mathrm{~g} / \mathrm{m}^{2}$ ) showed the lowest strength, the values were by approximately $20 \%$ lower compared to specimen E. 
Detailed results and comparison of the results of all the specimens are shown in Table 2.

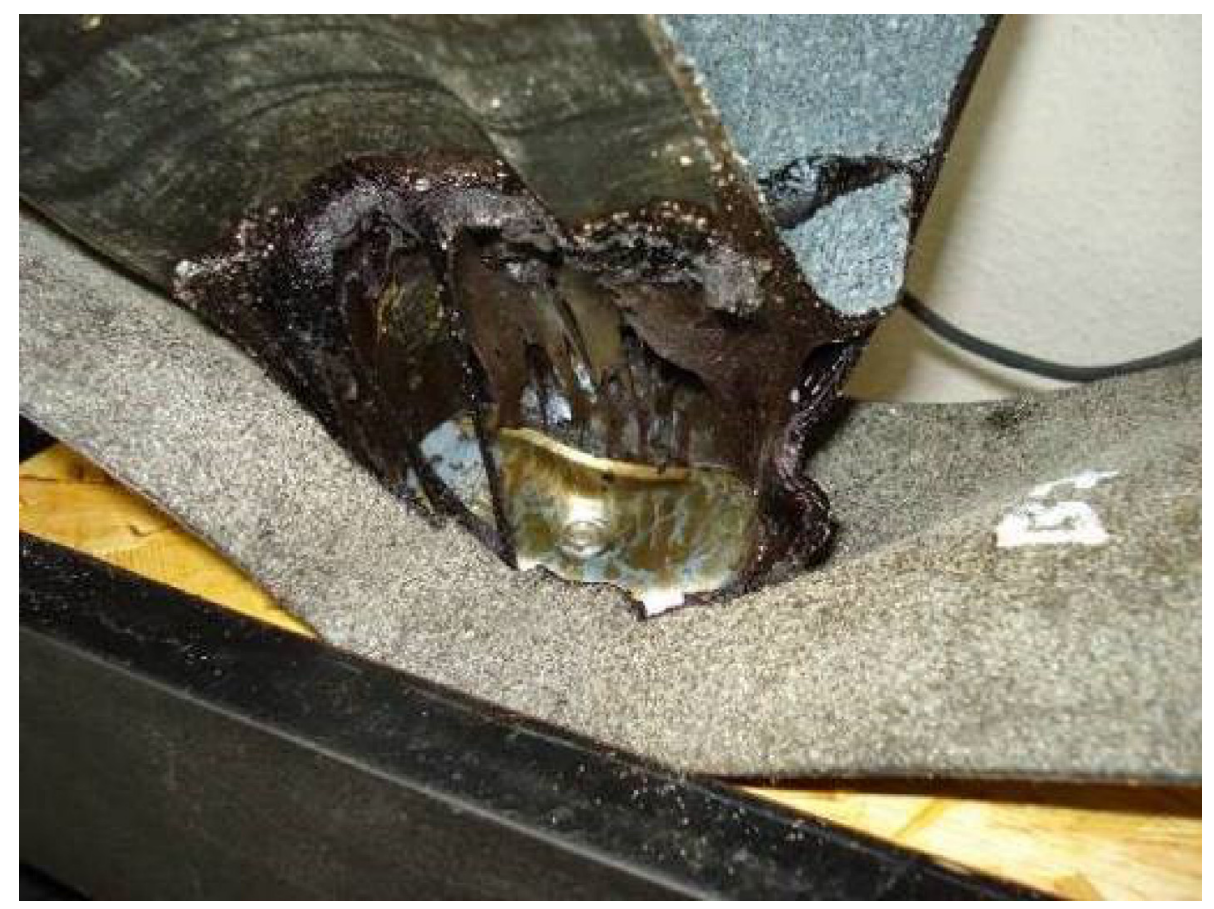

Fig. 6. Typical damage of the joint on specimen B. Source: [8].

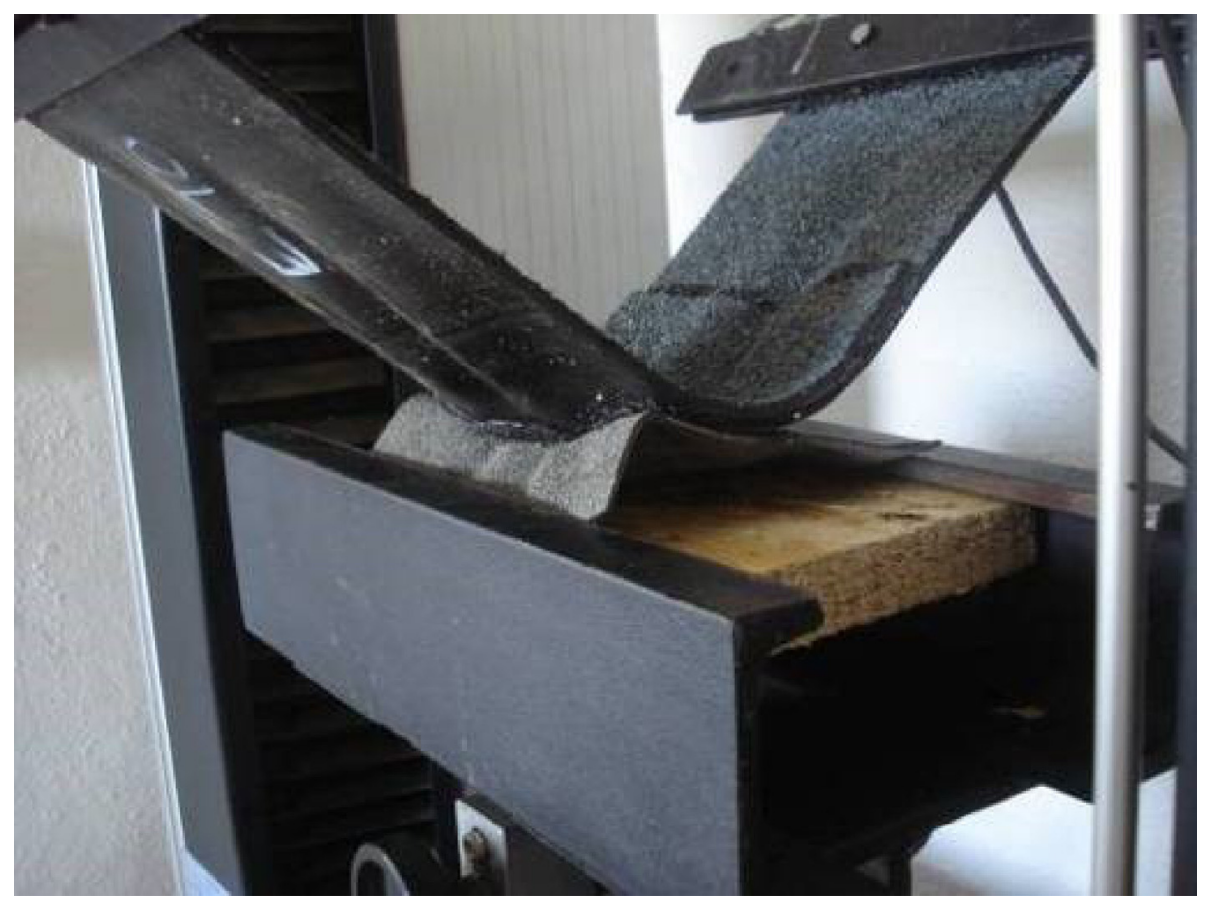

Fig. 7. No damage of the joint on specimen $\mathrm{E}$ is visible at the maximum tensile. Source: [8]. 
Table 2. Comparison of the test specimens

\begin{tabular}{|c|c|c|c|}
\hline Test specimen: & B & $\mathbf{E}$ & $\mathbf{F}$ \\
\hline Bitumen substance: & \multicolumn{3}{|c|}{ SBS modified } \\
\hline $\begin{array}{l}\text { Flexibility at low } \\
\text { temperatures: }\end{array}$ & \multicolumn{3}{|c|}{$-25^{\circ} \mathrm{C}$} \\
\hline Sheet thickness: & \multicolumn{3}{|c|}{$5.2 \mathrm{~mm}$} \\
\hline Carrier: & $\begin{array}{l}\text { PES longitudinally } \\
\text { reinforced, } 180 \mathrm{~g} / \mathrm{m} 2\end{array}$ & $\begin{array}{l}\text { PES } 230 \mathrm{~g} / \mathrm{m} 2, \text { not } \\
\text { reinforced }\end{array}$ & $\begin{array}{l}\text { PES reinforced on } \\
\text { both sides, } 180 \mathrm{~g} / \mathrm{m} 2\end{array}$ \\
\hline Overlap width: & \multicolumn{3}{|c|}{$100 \mathrm{~mm}$} \\
\hline $\begin{array}{c}\text { The highest tensile } \\
\text { strength: }\end{array}$ & $\begin{array}{l}\text { longitudinally: } 900 \\
( \pm 200) \mathrm{N} / 50 \mathrm{~mm} \\
\text { transversally: } 700 \\
( \pm 150) \mathrm{N} / 50 \mathrm{~mm}\end{array}$ & $\begin{array}{l}\text { longitudinally: } 950 \\
( \pm 200) \mathrm{N} / 50 \mathrm{~mm} \\
\text { transversally: } 850 \\
( \pm 150) \mathrm{N} / 50 \mathrm{~mm}\end{array}$ & $\begin{array}{l}\text { longitudinally: } 900 \\
( \pm 200) \mathrm{N} / 50 \mathrm{~mm} \\
\text { transversally: } 650 \\
( \pm 150) \mathrm{N} / 50 \mathrm{~mm}\end{array}$ \\
\hline Ductility: & $\begin{array}{c}\text { longitudinally and } \\
\text { transversally: } \\
50( \pm 10) \%\end{array}$ & $\begin{array}{c}\text { longitudinally and } \\
\text { transversally: } \\
50( \pm 10) \%\end{array}$ & $\begin{array}{c}\text { longitudinally and } \\
\text { transversally: } \\
45( \pm 10) \%\end{array}$ \\
\hline Mean value: & $1,624.5 \mathrm{~N}$ & $1,856.8 \mathrm{~N}$ & $1,488.3 \mathrm{~N}$ \\
\hline Standard deviation: & $127.6 \mathrm{~N}$ & $97.4 \mathrm{~N}$ & $131.6 \mathrm{~N}$ \\
\hline Variation coefficient: & $7.9 \%$ & $5.2 \%$ & $8.8 \%$ \\
\hline
\end{tabular}

Higher square weight of the PES rug increases resistance of a bitumen sheet against mechanical damage (tearing against the shank or the pressure washer of the fastening element) when exposed to stress. For combined carriers manufacturers present their total square weights, i.e. the PES rug including the reinforcement glass fibres. In the instance of the PES rug reinforced on both sides the proportion of the glass fibres in the total weight of the carrier is higher, so the weight of the PES rug itself is lower. This might explain why the bitumen sheet with longitudinally reinforced PES rug (specimen B) achieved higher strengths than the sheet with a PES rug reinforced in both directions (specimen F).

In the bitumen sheets reinforced with combined carrier no gradual cracking of the individual glass fibres that reinforce the carrier was visible during tensioning and before the rupture. In the case of the combined carriers the parameters depend on the particular type square weight, location and connection of the reinforcement fibres to the PES rug affect the resulting strengths and ductility of the carrier.

The results of this comparison should however be understood in wider context - on the base of the above described results application of bitumen sheets with carriers of non reinforced PES rugs cannot be preferred. Application of combined carriers in single-layer mechanically fastened systems provides irreplaceable advantages.

\section{Conclusion}

The performed measurements showed that the strength of a joint of mechanically fastened bitumen sheet grows with the square weight of the PES rug used in the carrier of the bitumen sheet.

In combined carriers the total weight is lowered by the weight of the glass reinforcement fibres, which might lead to reduction of the final strength compared to an unreinforced carrier. Application of combined carriers in single-layer mechanically fastened systems however provides irreplaceable advantages. 
This paper has been worked out under the project No. LO1408 "AdMaS UP - Advanced Materials, Structures and Technologies", supported by Ministry of Education, Youth and Sports under the „National Sustainability Programme I”.

\section{References}

1. ČSN EN 13707+A2, Waterproofing sheets and foils - Reinforced roof waterproofing bitumen sheets - Definitions and characteristics (The Institute of Technical Standardization, Metrology and State Testing, Prague, 2009)

2. ČSN EN 12316-1, Waterproofing sheets and foils - Part 1: Roof waterproofing bitumen sheets - Determination of peel resistance of joints (Czech Standards Institution, Prague, 2000)

3. ČSN EN 12317-1, Waterproofing sheets and foils - Part 1: Roof waterproofing bitumen sheets - Determination of shear resistance in joints (Czech Standards Institution, Prague, 2000)

4. R. Smolka, T. Petříček, P. Kacálek, enviBUILD 2014 - Buildings and Environment (Brno, 2014)

5. T. Petř́íček, P. Kacálek, R. Smolka, AMS 1041, 71-74 (2014)

6. J. Plachý, Bitumen sheet joints under the influence of temperature and time in the composition of single-membrane roofs (Doctoral thesis, Brno University of Technology, Faculty of Civil Engineering, Brno, 2005)

7. ETAG 006. European Technical Approval Guideline - Systems of Mechanically Fastened Flexible Roof Waterproofing Membranes (European Organisation for Technical Assessment - EOTA, Brussels, 2000)

8. T. Petŕíček, Adhesion of joints of mechanically fastened bitumen sheets (Doctoral thesis, Brno University of Technology, Faculty of Civil Engineering, Brno, 2013) 